\title{
Regulation of protein tyrosine kinases in tumour cells by the transcription factor Ets-1
}

\author{
JENS CLAUS HAHNE, SEBASTIAN KUMMER, LUKAS CARL HEUKAMP, TANJA FUCHS, \\ MARINA GUN, BERIT LANGER, ALEXANDER VON RUECKER and NICOLAS WERNERT
}

Institute of Pathology, University of Bonn, 53011 Bonn, Germany

Received May 21, 2009; Accepted July 13, 2009

DOI: 10.3892/ijo_00000413

\begin{abstract}
Tyrosine phosphorylation is one of the key covalent modifications that occurs in multicellular organisms as a result of intercellular communication. The family of tyrosine kinases (PTKs) are responsible for part of the cellular phosphorylation and are involved in a broad variety of cellular functions including differentiation, proliferation, migration, invasion, angiogenesis and survival under physiological as well as pathological conditions. Aberration in PTK signalling occurs in inflammatory diseases and diabetes, and aberrant expression can lead to benign proliferative conditions as well as to various forms of cancer. Indeed, more than $70 \%$ of the known oncogenes and proto-oncogenes involved in cancer code for PTKs. Therefore, these enzymes are now used as targets in the treatment of different tumours. Ets-1 is a transcription factor expressed in a number of human malignancies with demonstrated roles within both neoplastic cells and tumour stroma. These roles include stimulation of tumour cell proliferation and invasion as well as tumour angiogenesis. Database searches have revealed that ETS binding sites are present in several promoters of PTK-encoding genes. We investigated the role of Ets- 1 in transcriptional regulation of a panel of 89 PTKs in epithelial HeLa tumour cells. In this study, HeLa cells stably overexpressing and underexpressing Ets-1 were used for real-time PCR analysis of all known human PTKs. The results suggest that Ets-1 is an essential transcription factor that cannot be substituted by other members of the ETS family. Transcription of most PTKs was found to be increased by Ets-1. In contrast Ets-1 seems to act as a transcriptional repressor of other PTKs. The data presented here underscore the importance of Ets-1 in tumour development and progression.
\end{abstract}

\section{Introduction}

Protein tyrosine kinases (PTKs) are enzymes that catalyze the transfer of the $\gamma$ phosphate of ATP to tyrosine residues on

Correspondence to: Dr Nicolas Wernert, Institute of Pathology, University of Bonn, P.O. Box 2120, 53011 Bonn, Germany

E-mail: nicolas.wernert@ukb.uni-bonn.de

Key words: Ets-1, tyrosine kinases, transcriptional regulation, HeLa cells protein substrates. By phosphorylation of tyrosine residues on receptors or downstream signalling proteins, their enzymatic activity is modulated $(1,2)$. PTKs are involved in most cellular signalling pathways and regulate many key functions such as proliferation, differentiation, migration, metabolic changes and apoptosis (3-14). New blood vessel development relies on the concerted action of several subfamilies of PTKs and their cognate ligands as well (15). Due to the involvement of PTKs in such important processes, a stringent regulation of their expression and activity is necessary for maintaining normal cellular functions (16). The importance of PTKs in health and disease is further underscored by the existence of aberrations in PTK signalling occurring in cancer, inflammatory diseases and diabetes (17-19). Dysregulation of PTKs through point mutations or overexpression can lead to various forms of cancer as well as benign proliferative conditions $(5,20-22)$. Indeed, more than $70 \%$ of known oncogenes and proto-oncogenes involved in cancer encode PTKs (23). Another oncogenic mechanism involving PTK are translocations creating fusion proteins with constitutive expression or activity. Among such translocations are ETV-6/ ABL1, ETV-6/FRK, TEL/PDGFR- $\beta$ fusing translocated PTKs and members of the ETS transcription factor family (24-28). ETS family members are widely expressed and are involved in basic cellular functions such as proliferation, apoptosis, angiogenesis, differentiation and migration (29-40). These functions are critical for the development of cancer (41). All ETS members share a specific DNA binding domain, called the ETS domain, which consists of approximately 80 amino acids with 4 tryptophane repeats (42). It has been shown that two-thirds of the 27 human ets genes are expressed ubiquitously and that the DNA binding of ETS proteins has overlapping specificities (43).

Several PTKs interact with the Ras/Raf/MAP or with the MEK $1 /$ ERK $1 / 2$ pathway which is known to result in transcriptional activation of Ets-1 (44-50) which is the prototype of the ETS transcription factor family (51).

Furthermore, ETS binding sites have been found in several PTK promoters (52-58) suggesting a role for Ets- 1 in the transcriptional regulation of PTKs. Since an expression analysis of all known PTKs in correlation to the expression level of Ets-1 in human tumour cells has not yet been carried out, we determined expression levels of all known PTKs by real-time PCR in stably Ets-1-overexpressing and -underexpressing HeLa cells which we have used and characterized in previous studies (32). We showed that Ets-1 is an essential 
transcriptional activator for most PTKs including EGFR, FGFR4, JAK3, c-KIT and MET, while the expression of 10 out of 89 PTKs (including EPHA3, EPHA4, EPHB2, EPHB3 and PDGFR- $\beta$ ) were suppressed. These data suggest a regulatory role of Ets-1 in a number of PTKs involved in tumour development and progression.

\section{Materials and methods}

Cell culture. The establishment of Ets-1-overexpressing and -underexpressing HeLa cell lines has been previously described (32). Briefly, the plasmids pcDNA3.1h-ets- 1 and pcDNA3.1h-ets- 1 inverse, respectively, were transfected into the cells by the calcium phosphate method (59). Twenty-four hours after transfection, selection was started using $400 \mu \mathrm{g} /$ ml G418 (Invitrogen). Ets-1-overexpressing (HeLa Ets-1) and -underexpressing (HeLa inverse) cells were selected from pooled populations of transfected cells in order to avoid clonal variations.

All cell lines were cultured in Dulbecco's modified Eagle's medium (DMEM) (Invitrogen) supplemented with antibiotics and $10 \%$ heat-inactivated fetal calf serum.

Reverse transcription polymerase chain reaction (RT-PCR). Total RNA was extracted from cell monolayers (RNeasy Kit, Qiagen), and the quality was assessed using the Agilent Bioanalyzer 2100 (Agilent Technologies).

For samples with a RIN factor $>9$, cDNAs were constructed by reverse transcription in a $10-\mu 1$ reaction volume containing $2 \mu \mathrm{g}$ of total cellular RNA, $1 \mu \mathrm{l}$ dNTPs $(10 \mathrm{mM}), 1 \mu \mathrm{l}$ of random hexamer primers $(10 \mathrm{mM})$, and RNase-free water. After incubation at $65^{\circ} \mathrm{C}$ for $5 \mathrm{~min}$, the reaction mixture was placed on ice for $1 \mathrm{~min}$. Then $2 \mu 1$ of RT buffer (Invitrogen), $4 \mu 1 \mathrm{MgCl}_{2}(25 \mathrm{mM}), 2 \mu \mathrm{l}$ of $0.1 \mathrm{mM}$ DTT and $1 \mu \mathrm{l}$ RNaseOUT $^{\mathrm{TM}}$ Recombinant RNase Inhibitor (Invitrogen) were added. After incubation at $42^{\circ} \mathrm{C}$ for $2 \mathrm{~min}$, $1 \mu 1$ of Superscript II Reverse Transcriptase (50 units/ $\mu 1$ ) (Invitrogen) was added for the transcription at $42^{\circ} \mathrm{C}$ for $1 \mathrm{~h}$. Inactivation of the enzyme was performed by heating at $70^{\circ} \mathrm{C}$ for $15 \mathrm{~min}$. RNA was removed by addition of $1 \mu 1 \mathrm{RNaseH}$ and incubation at $37^{\circ} \mathrm{C}$ for $20 \mathrm{~min}$.

Real-time RT-PCR. PCR reactions were performed using the TaqMan Low Density Array System (Applied Biosystems) (60-63). Arrays with four sets of 96 genes were designed, and each reaction was performed in duplicate. Primer/probe sets were selected from a large pool of TaqMan Gene Expression Assays (Applied Biosystems) that are predesigned and tested to strictly match system-immanent criteria of uniform PCR temperature profile and PCR efficiency. Beside the 89 tyrosine kinases, 5 putative endogenous control genes (HPRT1, UBC, G6PDH, RNApolymerase II, 18sRNA) were included on each array. All amplicons span an exon-exon-junction to achieve mRNA specificity and are of two-digit-bp length. Primer/probe sets are spotted on a custom 384-well card during fabrication at the manufacturer. cDNA was diluted to a final concentration of $8 \mathrm{ng} / \mu \mathrm{l}$ and mixed 1:1 with $2 \mathrm{X}$ TaqMan Universal PCR Master Mix (Applied Biosystems). One hundred microliters containing $400 \mathrm{ng}$ cDNA was loaded into each fill port and
A

\begin{tabular}{|c|c|c|c|c|}
\hline 0 & Exp & ression level & & $\overrightarrow{0}$ \\
\hline AATK-Hs00185425_m1 & & & & \\
\hline ABL2-Hs00270858_m1 & & & & \\
\hline ACK1-Hs00178648_m1 & & & & \\
\hline ALK-Hs00608289_m1 & & 7 & & \\
\hline BTK-Hs00163761_m1 & & & & \\
\hline CSF1R-Hs00234617_m1 & & & & \\
\hline CSK-Hs00177843_m1 & & 1 & & \\
\hline DDR1-Hs00233612_m1 & & in & & \\
\hline DDR2-Hs00178815_m1 & $\mapsto$ & & & \\
\hline DKFZp434C1418-Hs002 & 3_m1 & $\rightarrow$ & & \\
\hline EPHA1-Hs00178313_m1 & & & & \\
\hline EPHA2-Hs00171656_m1 & & & & \\
\hline EPHA5-Hs00300724_m1 & & & & \\
\hline EPHA8-Hs00184126_m1 & & & & \\
\hline ERBB3-Hs00176538_m1 & & & & \\
\hline ERBB4-Hs00171783_m1 & & & & \\
\hline FER-Hs00245497_m1 & & & & \\
\hline FGFR1-Hs00241111_m1 & & & & \\
\hline FGFR3-Hs00179829_m1 & & & & \\
\hline FGR-Hs00178340_m1 & & 믈 & & \\
\hline FLT3-Hs00174690_m1 & & & & \\
\hline FRK-Hs00176619_m1 & & & 4 & \\
\hline HCK_Hs00176654_m1 & & H & & \\
\hline IGF1R-Hs00609566_m1 & & & & \\
\hline INSR-Hs00169631_m1 & & & & \\
\hline
\end{tabular}

Figure 1A.

distributed through microchannels into the 48 reaction wells per filling port by centrifugation. Subsequent sealing of the microchannels prevented cross-contamination during PCR. The arrays were thermal cycled at $50^{\circ} \mathrm{C}$ for $2 \mathrm{~min}$ and $94.5^{\circ} \mathrm{C}$ for $10 \mathrm{~min}$, followed by 40 cycles at $97^{\circ} \mathrm{C}$ for $30 \mathrm{sec}$ and $59.7^{\circ} \mathrm{C}$ for $1 \mathrm{~min}$ on an Applied Biosystems $7900 \mathrm{HT}$ instrument.

Data processing. Absolute Ct-values were calculated using SDS 2.2 Software (Applied Biosystems) and transferred into the qBase Software (Micosoft Excel-Plug-In, Jo Vandesompele) for further analysis. Since normalization based on single housekeeping genes may not provide accurate results, we used a geometric mean of RNA-polymerase II and 18sRNA for normalizing, which showed the most stable expression across all samples. Calculations were based on an amplification efficiency of 1.95 which represents quite exactly the tested amplification efficiency of pre-designed TaqMan-assays (1.9-2.0, according to the manufacturer's instructions). The expression levels of the target genes were given relative to the calibrator sample HeLa Ets-1 with the standard error of mean calculated from replicate accuracy.

Immunocytochemistry. Cells grown in $1-\mathrm{cm}^{2}$ culture chambers (Nunc) were rinsed once with phosphate-buffered saline 
B

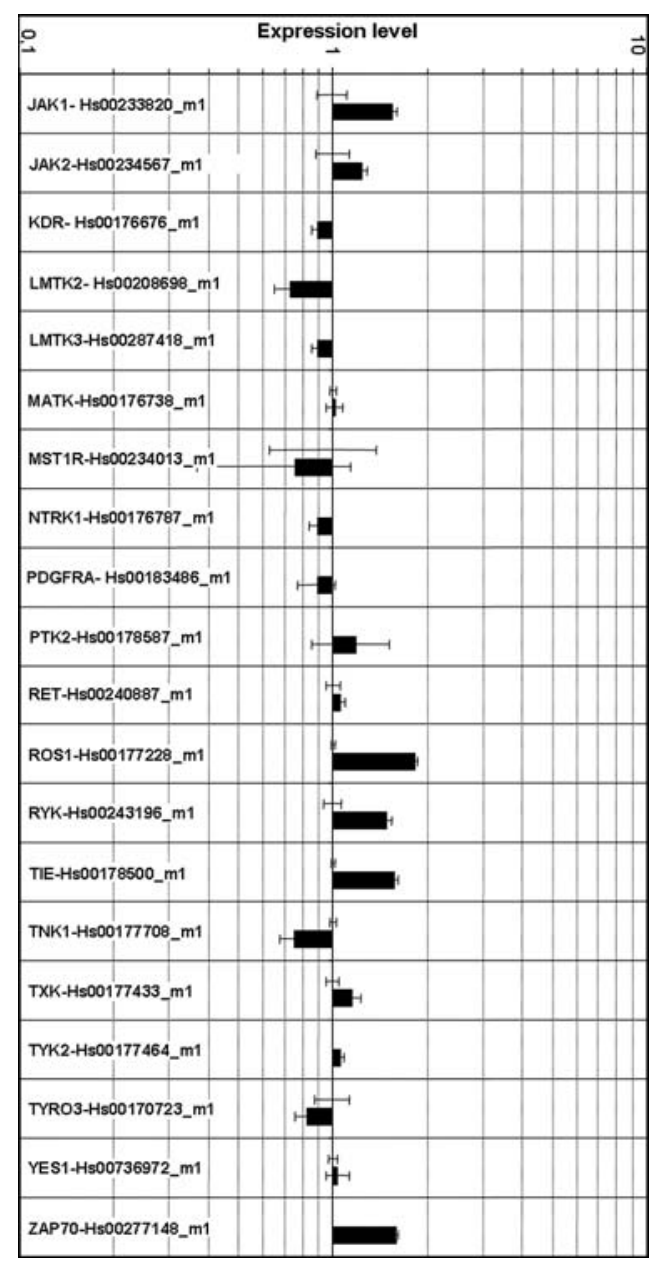

C

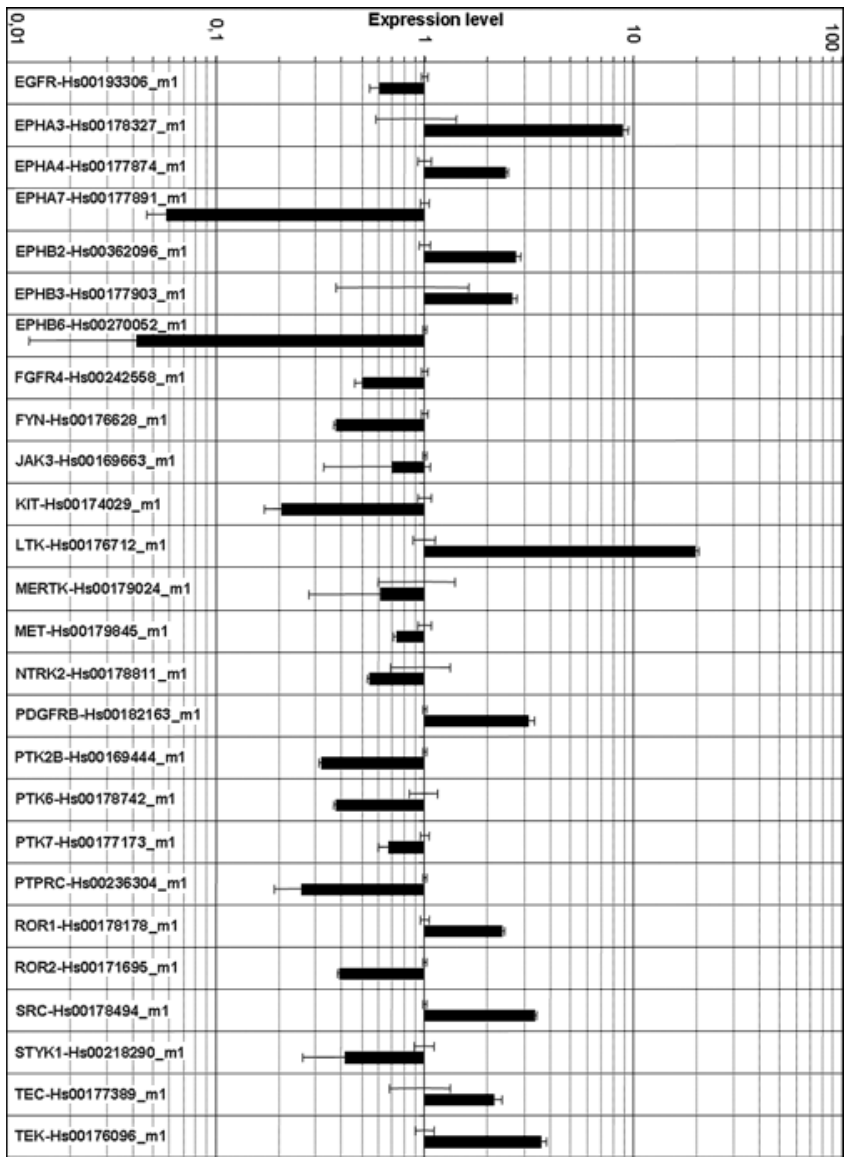

Figure 1. Real-time RT-PCR analysis of human PTKs. RT-PCR was performed with total RNA from HeLa Ets-1 and HeLa inverse cells, respectively, using the TaqMan Low Density Array System. The expression of 89 genes coding for human PTKs was measured in parallel. The mean value of 2 x 2 independent measurements is shown. The expression level in HeLa Ets-1 cells was set to 1. PTK expression levels in HeLa Ets-1 inverse cells are shown in relation to the expression rate in HeLa Ets- 1 cells. In A and B, differentially expressed PTKs exhibiting a difference of $\leq 1.5$ and in C, $\geq 1.5$ between HeLa Ets-1 and HeLa Ets-1 inverse cells are shown.

(PBS) (Life Technologies), twice with $70 \%$ ethanol and fixed in a mixture of ice cold methanol and ethanol $(1: 2 \mathrm{v}: \mathrm{v})$ at $4^{\circ} \mathrm{C}$ for 20 min. After washing twice with PBS, cells were stained with antibodies directed against PDGFR- $\beta(1: 1000$ dilution) (Santa Cruz Biotechnology), EGFR (1:25 dilution) (Dako), ZAP-70 (1:25 dilution) (Biosystems) or c-kit (1:25 dilution) (Dako). The cells were incubated with the primary antibody at $4^{\circ} \mathrm{C}$ for $12 \mathrm{~h}$. Detection of the primary antibody was carried out using the LSAB-peroxidase System (Dako) according to the manufacturer's instructions.

\section{Results}

We previously demonstrated effective overexpression or blockade of Ets-1 protein in HeLa Ets-1 and HeLa inverse cells (32). When examined by Western blotting, expression levels of proteins with phosphorylated tyrosine residues showed variations between wild-type (HeLa) cells, HeLa cells overexpressing (HeLa Ets-1) and underexpressing Ets-1 (HeLa inverse) (data not shown). We then evaluated the effect of Ets-1 on the mRNA expression of all known human protein tyrosine kinases (PTKs) by comparing HeLa Ets-1 and HeLa inverse cells.

As shown in Fig. 1, a broad variety of PTKs are differentially expressed in Ets-1-overexpressing und -underexpressing HeLa cell lines. The expression level in HeLa Ets-1 cells was set to 1 . The PTK expression levels in HeLa inverse cells are shown in relation to the expression rate in HeLa Ets-1 cells. In Fig. 1A and B the differentially expressed PTKs are summarized and show only a small difference $(\leq 1.5)$ between the two cell lines. In Fig. 1C the PTKs showing a $\geq 1.5$-fold change in expression are listed. It is evident that PTKs are regulated at the mRNA level by Ets-1. Ten PTKs (EPHA3, EPHA4, EPHB2, EPHB3, LTK, PDGFR- 3 , ROR1, SRC, TEC and TEK) had a higher RNA expression level in the HeLa inverse compared to the HeLa Ets-1 cells (Fig.1C). This suggests that the transcription of these PTKs is repressed by Ets-1. In contrast, 16 PTKs (EGFR, EPHA7, ERHB6, FGFR4, FYN, JAK3, c-KIT, MERTK, MET, NTRK2, PTK2B, PTK6, PTK7, PTPRC, ROR2 and STYK1) were found to have a reduced RNA expression level in the HeLa inverse compared to the HeLa 

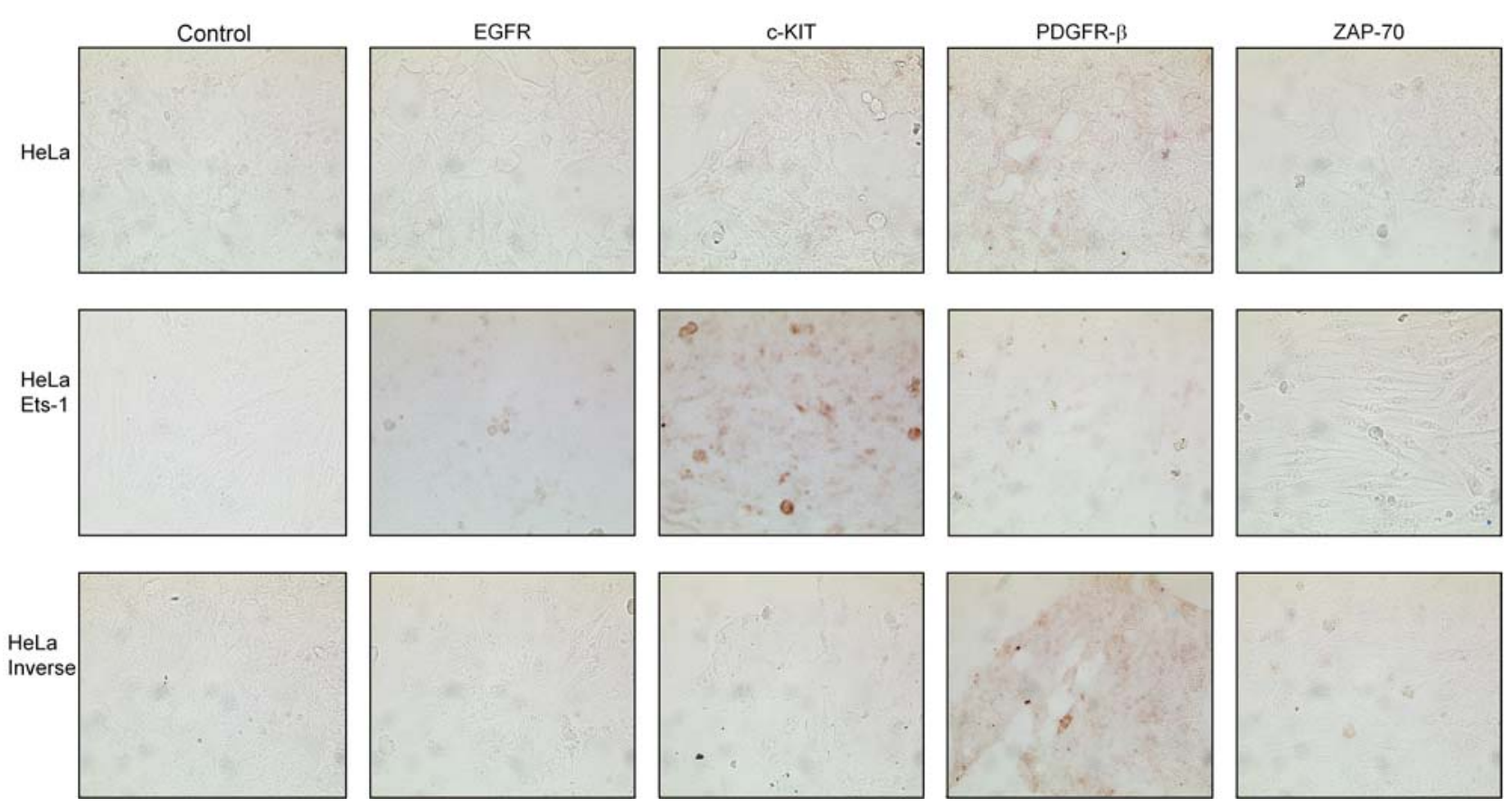

Figure 2. Immunohistochemical staining for EGFR, c-KIT, PDGFR-ß and ZAP-70 expression in HeLa, HeLa Ets-1 and HeLa Ets-1 inverse cell lines. Cells were fixed and stained with antibodies against EGFR, c-KIT, PDGFR-ß and ZAP-70. Images were captured at a 30-fold magnification.

Ets-1 cells (Fig. 1C). For these 16 PTKs, Ets-1 seems to be an essential transcriptional activator.

Twenty PTKs were not expressed in either cell line. These PTKs were ABL1, AXL, BLK, BMX, EPHB1, EPHB4, ERBB2, FES, FGFR2, INSRR, ITK, LCK, LYN, MERTK, MUSK, NTRK3, SRMS, SYK, VEGFR-1 and VEGFR-3.

The differential expression of selected PTKs was verified at the protein level by immunocytochemistry for EGFR, c-KIT, PDGFR- 3 and ZAP-70 (Fig. 2). Expression in the parental HeLa, HeLa Ets-1 and HeLa inverse cell lines is shown. Expression of EGFR was hardly detectable in HeLa Ets- 1 cells. Wild-type HeLa cells, as well as HeLa inverse cells did not show any expression of EGFR.

In contrast, an increased c-KIT expression was found in HeLa Ets-1 cells compared to HeLa and HeLa inverse cells. PDGFR- $\beta$ expression was enhanced in HeLa inverse cells in comparison to the two other cell lines. No significant ZAP70 expression was detected in the three cell lines correlating in essence to the results at the mRNA level.

In conclusion, differences in expression of 4 PTKs at the RNA level were observed at the protein level by immunocytochemistry.

\section{Discussion}

The Ets-1 gene has first been identified as the cellular precursor of the viral Ets-1 oncogene which, together with v-Myb, induces a mixed erythroleukemia in chickens (64). Ets-1 is now considered to be the prototype of the ETS family of transcription factors which now includes approximately 30 members $(42,51)$. All ETS transcription factors share a specific DNA binding domain composed of approximately 80 amino acids (ETS domain) (42) which mediates transactivation or repression of numerous target genes (65-71). In previous studies, we and others first related Ets-1 to new blood vessel formation including tumour vascularization (72-75). Subsequent studies revealed Ets-1 expression likewise within fibroblasts in the stroma of invasive human tumours (76). Stromal fibroblasts contribute to tumour invasion by the secretion of different matrix-degrading proteases. Their genes have been shown to be Ets-1 target genes in both fibroblasts and endothelial cells (77-80) which require invasive properties likewise for early steps of angiogenesis $(81,82)$. More rarely than in tumour stroma, Ets- 1 is expressed within neoplastic cells themselves, as we previously revealed in human breast cancers and melanomas as well as in rat C6 glioma and human HeLa cells $(32,34,83-85)$.

In human breast cancer cell lines, Ets-1 expression was proposed to be associated with in vitro invasiveness and epithelial-mesenchymal transition, linked to expression of vimentin, uPA, MMP-1 and MMP-3 and to a loss of E-cadherin (83). In normal madin-darby canine kidney (MDCK) cells, Ets-1 was a target of scatter factor/hepatocyte growth factor (SF/HGF) signalling through met receptor tyrosine kinase $(46-48,86)$. In these cells SF/HGF-induced Ets-1 expression was correlated with morphological changes through RASRAF-MEK-ERK signalling which activates Ets-1 (46-49). By overexpressing and blocking Ets-1 (through RNAi approaches and decoy oligonucleotides), we demonstrated that Ets-1 has roles in cell proliferation, migration and invasion in melanoma, C6 glioma and HeLa cell lines, and we identified several Ets-1 target genes such as MMP-1, -3, -9 and UPA as well as integrin $\beta 2$ and $\beta 3(32,34,84,85)$.

It is well established that PTKs are involved in most cellular signalling pathways and that they regulate cellular key functions such as proliferation, differentiation, migration, metabolic changes and anti-apoptotic signalling (3-14). In diabetes, inflammatory diseases and cancer, unregulated 
Table I. Promoter regions of tyrosine kinases encoding genes obtained from public available sequences (National Center for Biotechnology Information or Ensembl Genome Browser) were searched for the number of potential Ets-1 binding sites with the PATCH 1.0 public program. ${ }^{\mathrm{a}}$

\begin{tabular}{lccc}
\hline Tyrosine & x-fold mRNA & No.of & Described \\
kinase & expression & potential & Ets-1 \\
& differences in & Ets-1 binding & binding \\
HeLa inverse & sites in the & sites in the \\
compared to & promoter & literature \\
HeLa Ets-1 cells & region & \\
\hline
\end{tabular}

\begin{tabular}{|c|c|}
\hline LTK & 19.767 \\
\hline EPHA3 & 8.817 \\
\hline TEK & 3.575 \\
\hline $\mathrm{SRC}$ & 3.331 \\
\hline PDGFR- $ß$ & 3.109 \\
\hline EPHB2 & 2.726 \\
\hline EPHB3 & 2.624 \\
\hline 4EPHA4 & 2.445 \\
\hline ROR1 & 2.361 \\
\hline TEC & 2.124 \\
\hline ROS1 & 1.818 \\
\hline INSR & 1.786 \\
\hline ZAP70 & 1.587 \\
\hline CSK & 1.580 \\
\hline TIE & 1.568 \\
\hline JAK1 & 1.544 \\
\hline EPHA1 & 1.526 \\
\hline RYK & 1.485 \\
\hline FGFR1 & 1.436 \\
\hline FGFR3 & 1.389 \\
\hline FRK & 1.363 \\
\hline BTK & 1.353 \\
\hline ERBB3 & 1.335 \\
\hline EPHA8 & 1.246 \\
\hline JAK2 & 1.242 \\
\hline EPHA5 & 1.241 \\
\hline IGF1R & 1.241 \\
\hline ACK1 & 1.200 \\
\hline ALK & 1.200 \\
\hline PTK2 & 1.184 \\
\hline ERBB4 & 1.169 \\
\hline FER & 1.169 \\
\hline TXK & 1.145 \\
\hline ABL2 & 1.116 \\
\hline RET & 1.057 \\
\hline TYK2 & 1.052 \\
\hline DKFZp434C1418 & 1.042 \\
\hline YES1 & 1.035 \\
\hline MATK & 1.010 \\
\hline DDR1 & 0.907 \\
\hline FGR & 0.891 \\
\hline KDR & 0.891 \\
\hline LMTK3 & 0.891 \\
\hline NTRK1 & 0.891 \\
\hline
\end{tabular}

Table I. Continued.

\begin{tabular}{|c|c|c|c|}
\hline $\begin{array}{l}\text { Tyrosine } \\
\text { kinase }\end{array}$ & $\begin{array}{l}\mathrm{x} \text {-fold mRNA } \\
\text { expression } \\
\text { differences in } \\
\text { HeLa inverse } \\
\text { compared to } \\
\text { HeLa Ets-1 cells }\end{array}$ & $\begin{array}{l}\text { No.of } \\
\text { potential } \\
\text { Ets-1 binding } \\
\text { sites in the } \\
\text { promoter } \\
\text { region }\end{array}$ & $\begin{array}{l}\text { Described } \\
\text { Ets-1 } \\
\text { binding } \\
\text { sites in the } \\
\text { literature }\end{array}$ \\
\hline PDGFRA & 0.891 & 30 & (58) \\
\hline ЕРHA2 & 0.866 & 2 & \\
\hline TYRO3 & 0.823 & 3 & \\
\hline CSF1R & 0.820 & 4 & (57) \\
\hline MCK & 0.808 & & \\
\hline AATK & 0.803 & 3 & \\
\hline FLT3 & 0.764 & 1 & \\
\hline MST1R & 0.753 & 3 & \\
\hline TNK1 & 0.748 & 1 & \\
\hline MET & 0.740 & 5 & (54) \\
\hline LMTK2 & 0.731 & 6 & \\
\hline DDR2 & 0.701 & 2 & \\
\hline JAK3 & 0.696 & 13 & (91) \\
\hline PTK7 & 0.665 & 2 & \\
\hline MERTK & 0.612 & 7 & \\
\hline EGFR & 0.609 & 3 & (52) \\
\hline NTRK2 & 0.548 & 3 & \\
\hline FGFR4 & 0.500 & 1 & (89) \\
\hline STYK1 & 0.416 & 3 & \\
\hline ROR2 & 0.390 & 1 & \\
\hline PTK6 & 0.379 & 0 & \\
\hline FYN & 0.375 & 4 & \\
\hline PTK2B & 0.320 & 15 & \\
\hline PTPRC & 0.256 & 2 & \\
\hline KIT & 0.208 & 6 & (56) \\
\hline EPHA7 & 0.058 & 1 & \\
\hline EPHB6 & 0.042 & 2 & \\
\hline
\end{tabular}

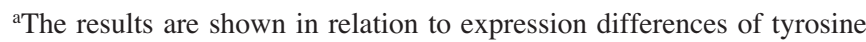
kinase transcripts between HeLa inverse and HeLa Ets-1 cells.

activation of PTKs is often observed (5,17-22,87). More than $70 \%$ of known oncogenes and proto-oncogenes involved in cancer code for PTKs (23). Furthermore, as mentioned previously, several types of cancers are caused by fusion proteins composed of translocated PTKs and members of the ETS transcription factor family (24-27). Since protein tyrosine kinases are the main intracellular transducers of signalling pathways leading to the most basic properties of tumour cells (proliferation, migration and invasion), we used HeLa cells to address the question of whether PTK-encoding genes are among Ets-1 target genes.

Our study specifically addressed Ets- 1 effects and ruled out any indirect effect that could be mediated by an endogenous activation of Ets-1. This is of particular interest since Ets-1 can act as both an upstream and downstream effector of signalling pathways. As downstream effector its activity is 
directly controlled by specific phosphorylations resulting in the ability to activate or repress specific target genes (51). As upstream effector it is responsible for the spatial and temporal expression of numerous growth factor receptors including PTKs (88).

The data presented here show that Ets- 1 is involved in the transcriptional regulation of a broad variety of PTKs in HeLa cells. It seems that Ets-1 is an essential transcriptional regulator for most PTKs in these cells and that this role cannot be substituted by other members of the ETS transcription factor family. One or more ETS binding sites have been identified in the promoter regions of several PTKs including EGFR, FGFR4, INSR, MET, EPHA3, c-KIT, CSF1R, PDGFR- $\alpha$, JAK3, BTK, VEGFR-1 and VEGFR-2 (52-58,72,89-92). The promoter regions of the other PTKs (obtained from public available sequences, National Center for Biotechnology Information or Ensembl Genome Browser) investigated in the present study were analyzed for potential ETS binding sites by the use of the PATCH 1.0 public program. In nearly all PTK promoter regions, potential Ets-1 binding sites were present suggesting direct effects of Ets-1 on the expression levels of PTK-encoding genes. Nevertheless, no direct correlation between the numbers of potential Ets-1 binding sites and the extent of regulation was evident as shown in Table I. For 6 PTK-encoding genes (EPHA4, TEC, ROS1, TIE, MCK and PTK6), no Ets-1 binding sites were detected in the promoter regions. In these cases the effects of Ets-1 on PTK expression was probably indirect and may have been caused by the regulation of other transcription factors and/or essential cofactors (93).

According to the present data, Ets-1 may act either as an activator or repressor for transcription of different PTKs. Such dual effects, transactivation or repression of different target genes by one transcription factor, have previously been described for other transcription factors likewise among which are members of the ETS family $(65-71,94)$.

PTK mRNA expression differences were verified by immunocytochemistry using 4 well-established antibodies (Fig. 2). The mRNA differences were verified for EGFR, c-KIT and PDGFR- $\beta$ at the protein level. For ZAP-70 no significant expression was detected in all cell lines correlating in essence to the results at the mRNA level.

In general, gene expression is the result of a cooperated action of many different factors, including both activators and repressors and their competition for specific DNA sequences in promoter regions. The transcription factors or cofactors determining the effect of Ets-1 as a repressor or activator for particular PTK genes remain to be identified.

In conclusion. Ets-1 seems to be involved, to a great degree, in the regulation of expression of many PTKs in HeLa tumour cells and thereby in many networks of intercellular communication important for cancer. These new findings, therefore, underscore the importance of the Ets-1 transcription factor for tumour development.

\section{Acknowledgements}

This study was supported by grants from the German Research Association (DFG) and the German Cancer Association (Deutsche Krebshilfe).

\section{References}

1. Monteiro HP, Rocha Oliveira CJ, Curcio MF, Moraes MS and Arai RJ: Tyrosine phosphorylation in nitric oxide-mediated signaling events. Methods Enzymol 396: 350-358, 2005.

2. Shen K, Hines AC, Schwarzer D, Pickin KA and Cole PA: Protein kinase structure and function analysis with chemical tools. Biochim Biophys Acta 1754: 65-78, 2005.

3. Chiarugi P: PTPs versus PTKs: the redox side of the coin. Free Radic Res 39: 353-364, 2005.

4. Medinger $M$ and Drevs J: Receptor tyrosine kinases and anticancer therapy. Curr Pharm Des 11: 1139-1149, 2005.

5. Lennartsson J and Ronnstrand L: The stem cell factor receptor/ c-kit as a drug target in cancer. Curr Cancer Drug Targets 6: 65-75, 2006.

6. Cohen LA and Guan JL: Mechanisms of focal adhesion kinase regulation. Curr Cancer Drug Targets 5: 629-643, 2005.

7. Ciampolillo A, De Tullio C and Giorgino F: The IGF-I/IGF-I receptor pathway: Implications in the pathophysiology of thyroid cancer. Curr Med Chem 12: 2881-2891, 2005.

8. Bolanos-Garcia VM: MET meet adaptors: functional and structural implications in downstream signalling mediated by the Met receptor. Mol Cell Biochem 276: 149-157, 2005.

9. Zhang J and Hughes S: Role of the ephrin and Eph receptor tyrosine kinase families in angiogenesis and development of the cardiovascular system. J Pathol 208: 453-461, 2006.

10. Urner F and Sakkas D: Protein phosphorylation in mammalian spermatozoa. Reproduction 125: 17-26, 2003.

11. Saltiel AR: Diverse signaling pathways in the cellular actions of insulin. Am J Physiol 270: E375-E385, 1996.

12. Jarpe MB, Widmann C, Knall C, et al: Anti-apoptotic versus pro-apoptotic signal transduction: checkpoints and stop signs along the road to death. Oncogene 17: 1475-1482, 1998.

13. Ostrander JH, Daniel AR, Lofgren K, Kleer CG and Lange CA: Breast tumor kinase (protein tyrosine kinase 6) regulates heregulin-induced activation of ERK5 and p38 MAP kinases in breast cancer cells. Cancer Res 67: 4199-4209, 2007.

14. Mohamed AJ, Yu L, Backesjo CM, et al: Bruton's tyrosine kinase (Btk): function, regulation, and transformation with special emphasis on the PH domain. Immunol Rev 228: 58-73, 2009.

15. Yancopoulos GD, Klagsbrun M and Folkman J: Vasculogenesis, angiogenesis, and growth factors: ephrins enter the fray at the border. Cell 93: 661-664, 1998.

16. Blume-Jensen P and Hunter T: Oncogenic kinase signalling. Nature 411: 355-365, 2001.

17. Bridges AJ: Therapeutic challenges of kinase and phosphatase inhibition and use in anti-diabetic strategy. Biochem Soc Trans 33: 343-345, 2005.

18. Kaminska B: MAPK signalling pathways as molecular targets for anti-inflammatory therapy - from molecular mechanisms to therapeutic benefits. Biochim Biophys Acta 1754: 253-262, 2005.

19. Karin M: Inflammation-activated protein kinases as targets for drug development. Proc Am Thorac Soc 2: 386-390; discussion 394-385, 2005.

20. Bignell G, Smith R, Hunter C, et al: Sequence analysis of the protein kinase gene family in human testicular germ-cell tumors of adolescents and adults. Genes Chromosomes Cancer 45: 42-46, 2006.

21. Jones AV and Cross NC: Oncogenic derivatives of plateletderived growth factor receptors. Cell Mol Life Sci 61: 2912-2923, 2004.

22. Tefferi A: Pathogenesis of myelofibrosis with myeloid metaplasia. J Clin Oncol 23: 8520-8530, 2005.

23. Levitzki A and Gazit A: Tyrosine kinase inhibition: an approach to drug development. Science 267: 1782-1788, 1995.

24. Himori K, Hatori M, Watanabe M, et al: Infantile fibrosarcoma of thigh - a case report. Ups J Med Sci 110: 85-93, 2005.

25. Hosoya N, Qiao Y, Hangaishi A, et al: Identification of a SRC-like tyrosine kinase gene, FRK, fused with ETV6 in a patient with acute myelogenous leukemia carrying a $t(6 ; 12)$ (q21;p13) translocation. Genes Chromosomes Cancer 42: 269-279, 2005.

26. Lannon CL, Martin MJ, Tognon CE, Jin W, Kim SJ and Sorensen PH: A highly conserved NTRK3 C-terminal sequence in the ETV6-NTRK3 oncoprotein binds the phosphotyrosine binding domain of insulin receptor substrate-1: an essential interaction for transformation. J Biol Chem 279: 6225-6234, 2004. 
27. Jin W, Yun C, Hobbie A, Martin MJ, Sorensen PH and Kim SJ: Cellular transformation and activation of the phosphoinositide3-kinase-Akt cascade by the ETV6-NTRK3 chimeric tyrosine kinase requires c-Src. Cancer Res 67: 3192-3200, 2007

28. Pham VN, Lawson ND, Mugford JW, et al: Combinatorial function of ETS transcription factors in the developing vasculature. Dev Biol 303: 772-783, 2007.

29. Cardone M, Kandilci A, Carella C, et al: The novel ETS factor TEL2 cooperates with Myc in B lymphomagenesis. Mol Cell Biol 25: 2395-2405, 2005

30. Gao Y, Ganss BW, Wang H, Kitching RE and Seth A: The RING finger protein RNF11 is expressed in bone cells during osteogenesis and is regulated by Ets1. Exp Cell Res 304: 127-135, 2005.

31. Garrett-Sinha LA, Hou P, Wang D, et al: Spi-1 and Spi-B control the expression of the Grap2 gene in B cells. Gene 353: $134-146,2005$

32. Hahne JC, Okuducu AF, Kaminski A, Florin A, Soncin F and Wernert N: Ets-1 expression promotes epithelial cell transformation by inducing migration, invasion and anchorageindependent growth. Oncogene 24: 5384-5388, 2005.

33. Hashiya N, Jo N, Aoki M, et al: In vivo evidence of angiogenesis induced by transcription factor Ets-1: Ets-1 is located upstream of angiogenesis cascade. Circulation 109: 3035-3041, 2004.

34. Rothhammer T, Hahne JC, Florin A, et al: The Ets-1 transcription factor is involved in the development and invasion of malignant melanoma. Cell Mol Life Sci 61: 118-128, 2004.

35. Zhou J, Chehab R, Tkalcevic J, et al: Elf5 is essential for early embryogenesis and mammary gland development during pregnancy and lactation. EMBO J 24: 635-644, 2005.

36. Li YY, Wu Y, Tsuneyama K, Baba T and Mukaida N: Essential contribution of Ets- 1 to constitutive Pim-3 expression in human pancreatic cancer cells. Cancer Sci 100: 396-404, 2009.

37. Dutta D, Ray S, Vivian JL and Paul S: Activation of the VEGFR1 chromatin domain: an angiogenic signal-ETS1/ HIF-2alpha regulatory axis. J Biol Chem 283: 25404-25413, 2008.

38. Shirakawa AK, Nagakubo D, Hieshima K, Nakayama T, Jin Z and Yoshie O: 1,25-Dihydroxyvitamin D3 induces CCR10 expression in terminally differentiating human B cells. J Immunol 180: 2786-2795, 2008.

39. John SA, Clements JL, Russell LM and Garrett-Sinha LA: Ets-1 regulates plasma cell differentiation by interfering with the activity of the transcription factor Blimp-1. J Biol Chem 283: 951-962, 2008

40. Oettgen P, Alani RM, Barcinski MA, et al: Isolation and characterization of a novel epithelium-specific transcription factor, ESE-1, a member of the ets family. Mol Cell Biol 17: 4419-4433, 1997.

41. Seth A and Watson DK: ETS transcription factors and their emerging roles in human cancer. Eur J Cancer 41: 2462-2478, 2005.

42. Wasylyk B, Hahn SL and Giovane A: The Ets family of transcription factors. Eur J Biochem 211: 7-18, 1993.

43. Hollenhorst PC, Jones DA and Graves BJ: Expression profiles frame the promoter specificity dilemma of the ETS family of transcription factors. Nucleic Acids Res 32: 5693-5702, 2004.

44. Mahon ES, Hawrysh AD, Chagpar RB, Johnson LM and Anderson DH: A-Raf associates with and regulates plateletderived growth factor receptor signalling. Cell Signal 17: 857-868, 2005

45. Schoffski P, Dumez H, Clement P, et al: Emerging role of tyrosine kinase inhibitors in the treatment of advanced renal cell cancer: a review. Ann Oncol 17: 1185-1196, 2006.

46. Fafeur V, Tulasne D, Queva C, et al: The ETS1 transcription factor is expressed during epithelial-mesenchymal transitions in the chick embryo and is activated in scatter factor-stimulated MDCK epithelial cells. Cell Growth Differ 8: 655-665, 1997.

47. Paumelle R, Tulasne D, Kherrouche Z, et al: Hepatocyte growth factor/scatter factor activates the ETS1 transcription factor by a RAS-RAF-MEK-ERK signaling pathway. Oncogene 21: 2309-2319, 2002.

48. Paumelle R, Tulasne D, Leroy C, Coll J, Vandenbunder B and Fafeur V: Sequential activation of ERK and repression of JNK by scatter factor/hepatocyte growth factor in madin-darby canine kidney epithelial cells. Mol Biol Cell 11: 3751-3763, 2000.

49. Tulasne D, Paumelle R, Leroy C, Reveneau S, Vandenbunder B and Fafeur V: Involvement of RAS-ERK signaling in multiple biological responses to HGF/SF. Ann NY Acad Sci 973: 105-108, 2002.
50. Goetze S, Kintscher U, Kaneshiro K, et al: TNFalpha induces expression of transcription factors c-fos, Egr-1, and Ets-1 in vascular lesions through extracellular signal-regulated kinases 1/2. Atherosclerosis 159: 93-101, 2001.

51. Sharrocks AD: The ETS-domain transcription factor family. Nat Rev Mol Cell Biol 2: 827-837, 2001.

52. Johnson AC, Ishii S, Jinno Y, Pastan I and Merlino GT: Epidermal growth factor receptor gene promoter. Deletion analysis and identification of nuclear protein binding sites. J Biol Chem 263: 5693-5699, 1988.

53. Cameron KE, Resnik J and Webster NJ: Transcriptional regulation of the human insulin receptor promoter. J Biol Chem 267: 17375-17383, 1992.

54. Gambarotta G, Boccaccio C, Giordano S, Ando M, Stella MC and Comoglio PM: Ets up-regulates MET transcription. Oncogene 13: 1911-1917, 1996.

55. Dottori M, Down M, Huttmann A, Fitzpatrick DR and Boyd AW: Cloning and characterization of EphA3 (Hek) gene promoter: DNA methylation regulates expression in hematopoietic tumor cells. Blood 94: 2477-2486, 1999.

56. Ratajczak MZ, Perrotti D, Melotti P, et al: Myb and ets proteins are candidate regulators of c-kit expression in human hematopoietic cells. Blood 91: 1934-1946, 1998

57. Reddy MA, Yang BS, Yue X, et al: Opposing actions of c-ets/ PU.1 and c-myb protooncogene products in regulating the macrophage-specific promoters of the human and mouse colony-stimulating factor-1 receptor (c-fms) genes. J Exp Med 180: 2309-2319, 1994

58. Bonello MR, Bobryshev YV and Khachigian LM: Peroxideinducible Ets- 1 mediates platelet-derived growth factor receptor-alpha gene transcription in vascular smooth muscle cells. Am J Pathol 167: 1149-1159, 2005.

59. Graham FL and van der Eb AJ: Transformation of rat cells by DNA of human adenovirus 5. Virology 54: 536-539, 1973.

60. Antonov J, Goldstein DR, Oberli A, et al: Reliable gene expression measurements from degraded RNA by quantitative real-time PCR depend on short amplicons and a proper normalization. Lab Invest 85: 1040-1050, 2005.

61. Marionneau C, Couette B, Liu J, et al: Specific pattern of ionic channel gene expression associated with pacemaker activity in the mouse heart. J Physiol 562: 223-234, 2005.

62. Tenedini E, Fagioli ME, Vianelli N, et al: Gene expression profiling of normal and malignant CD34-derived megakaryocytic cells. Blood 104: 3126-3135, 2004.

63. Abruzzo LV, Lee KY, Fuller A, et al: Validation of oligonucleotide microarray data using microfluidic low-density arrays: a new statistical method to normalize real-time RT-PCR data. Biotechniques 38: 785-792, 2005

64. Leprince D, Gegonne A, Coll J, et al: A putative second cellderived oncogene of the avian leukaemia retrovirus E26. Nature 306: 395-397, 1983.

65. Baker KM, Wei G, Schaffner AE and Ostrowski MC: Ets-2 and components of mammalian SWI/SNF form a repressor complex that negatively regulates the BRCA 1 promoter. J Biol Chem 278: 17876-17884, 2003

66. Maurer P, T'Sas F, Coutte L, et al: FEV acts as a transcriptional repressor through its DNA-binding ETS domain and alaninerich domain. Oncogene 22: 3319-3329, 2003.

67. Meraro D, Gleit-Kielmanowicz M, Hauser H and Levi BZ: IFN-stimulated gene 15 is synergistically activated through interactions between the myelocyte/lymphocyte-specific transcription factors, PU.1, IFN regulatory factor-8/IFN consensus sequence binding protein, and the IFN regulatory factor-4: characterization of a new subtype of IFNstimulated response element. J Immunol 168: 6224-6231, 2002.

68. Sgouras DN, Athanasiou MA, Beal GJ Jr, Fisher RJ, Blair DG and Mavrothalassitis GJ: ERF: an ETS domain protein with strong transcriptional repressor activity, can suppress etsassociated tumorigenesis and is regulated by phosphorylation during cell cycle and mitogenic stimulation. EMBO J 14: 4781-4793, 1995

69. Soudant N, Albagli O, Dhordain P, Flourens A, Stehelin D and Leprince D: A residue of the ETS domain mutated in the v-ets oncogene is essential for the DNA-binding and transactivating properties of the ETS- 1 and ETS-2 proteins. Nucleic Acids Res 22: $3871-3879,1994$

70. Starck J, Cohet N, Gonnet C, et al: Functional cross-antagonism between transcription factors FLI-1 and EKLF. Mol Cell Biol 23: $1390-1402,2003$ 
71. Waga K, Nakamura Y, Maki K, et al: Leukemia-related transcription factor TEL accelerates differentiation of Friend erythroleukemia cells. Oncogene 22: 59-68, 2003.

72. Valter MM, Hugel A, Huang HJ, et al: Expression of the Ets-1 transcription factor in human astrocytomas is associated with Fms-like tyrosine kinase-1 (Flt-1)/vascular endothelial growth factor receptor-1 synthesis and neoangiogenesis. Cancer Res 59: 5608-5614, 1999.

73. Vandenbunder B, Pardanaud L, Jaffredo T, Mirabel MA and Stehelin D: Complementary patterns of expression of c-ets 1, $\mathrm{c}-\mathrm{myb}$ and $\mathrm{c}-\mathrm{myc}$ in the blood-forming system of the chick embryo. Development 107: 265-274, 1989.

74. Wernert N, Raes MB, Lassalle P, et al: c-ets1 proto-oncogene is a transcription factor expressed in endothelial cells during tumor vascularization and other forms of angiogenesis in humans. Am J Pathol 140: 119-127, 1992.

75. Wernert N, Stanjek A, Kiriakidis S, et al: Inhibition of angiogenesis in vivo by ets- 1 antisense oligonucleotides inhibition of Ets-1 transcription factor expression by the antibiotic fumagillin. Angew Chem Int Ed Engl 38: 3228-3231, 1999.

76. Wernert N, Gilles F, Fafeur V, et al: Stromal expression of c-Ets1 transcription factor correlates with tumor invasion. Cancer Res 54: 5683-5688, 1994.

77. Hahne JC, Fuchs T, El Mustapha H, Okuducu AF, Bories JC and Wernert N: Expression pattern of matrix metalloproteinase and TIMP genes in fibroblasts derived from Ets-1 knock-out mice compared to wild-type mouse fibroblasts. Int J Mol Med 18: 153-159, 2006

78. Baillat D, Leprivier G, Regnier D, et al: Stromelysin-1 expression is activated in vivo by Ets-1 through palindromic head-to-head Ets binding sites present in the promoter. Oncogene 25: 5764-5776, 2006.

79. Behrens P, Rothe M, Wellmann A, Krischler J and Wernert N The Ets- 1 transcription factor is up-regulated together with MMP 1 and MMP 9 in the stroma of pre-invasive breast cancer. J Pathol 194: 43-50, 2001

80. Naito S, Shimizu S, Matsuu M, et al: Ets-1 upregulates matrix metalloproteinase-1 expression through extracellular matrix adhesion in vascular endothelial cells. Biochem Biophys Res Commun 291: 130-138, 2002.

81. Chakraborti S, Mandal M, Das S, Mandal A and Chakraborti T: Regulation of matrix metalloproteinases: an overview. Mol Cell Biochem 253: 269-285, 2003

82. Oikawa T and Yamada T: Molecular biology of the Ets family of transcription factors. Gene 303: 11-34, 2003.
83. Gilles C, Polette M, Birembaut P, Brunner N and Thompson EW: Expression of c-ets-1 mRNA is associated with an invasive, EMT-derived phenotype in breast carcinoma cell lines. Clin Exp Metastasis 15: 519-526, 1997.

84. Sahin A, Velten M, Pietsch T, et al: Inactivation of Ets 1 transcription factor by a specific decoy strategy reduces rat C6 glioma cell proliferation and MMP-9 expression. Int J Mol Med 15: 771-776, 2005.

85. Sahin A, Vercamer C, Kaminski A, et al: Dominant-negative inhibition of Ets 1 suppresses tumor growth, invasion and migration in rat C6 glioma cells and reveals differentially expressed Ets 1 target genes. Int J Oncol 34: 377-389, 2009.

86. Tulasne D, Paumelle R, Weidner KM, Vandenbunder B and Fafeur V: The multisubstrate docking site of the MET receptor is dispensable for MET-mediated RAS signaling and cell scattering. Mol Biol Cell 10: 551-565, 1999.

87. Seeger FH, Chen L, Spyridopoulos I, Altschmied J, Aicher A and Haendeler J: Downregulation of ETS rescues diabetesinduced reduction of endothelial progenitor cells. PLoS ONE 4: e4529, 2009.

88. Yordy JS and Muise-Helmericks RC: Signal transduction and the Ets family of transcription factors. Oncogene 19: 6503-6513, 2000.

89. Yu S, Asa SL and Ezzat S: Fibroblast growth factor receptor 4 is a target for the zinc-finger transcription factor Ikaros in the pituitary. Mol Endocrinol 16: 1069-1078, 2002.

90. Kappel A, Schlaeger TM, Flamme I, Orkin SH, Risau W and Breier G: Role of SCL/Tal-1, GATA, and ets transcription factor binding sites for the regulation of flk-1 expression during murine vascular development. Blood 96: 3078-3085, 2000.

91. Aringer M, Hofmann SR, Frucht DM, et al: Characterization and analysis of the proximal Janus kinase 3 promoter. J Immunol 170: 6057-6064, 2003.

92. Sideras P, Muller S, Shiels H, et al: Genomic organization of mouse and human Bruton's agammaglobulinemia tyrosine kinase (Btk) loci. J Immunol 153: 5607-5617, 1994.

93. Matis C, Chomez P, Picard J and Rezsohazy R: Differential and opposed transcriptional effects of protein fusions containing the VP16 activation domain. FEBS Lett 499: 92-96, 2001.

94. Roy S, Garges S and Adhya S: Activation and repression of transcription by differential contact: two sides of a coin. J Biol Chem 273: 14059-14062, 1998. 